\title{
Contact force exerted on the maxillary incisors by direct laryngoscopy with McGrath video laryngoscope in predicted difficult intubation
}

\section{Doddy Setiawan'}

Tjokorda Gde Agung Senapathi ${ }^{2}$

I Gede Budiarta ${ }^{3}$

I Gusti Ngurah Mahaalit Aribawa ${ }^{3}$

'Resident at Department of Anesthesiology, Pain Management, and Intensive Care, Udayana University, Sanglah General Hospital, DenpasarBali, Indonesia

${ }^{2}$ Associate Professor of Department of Anesthesiology, Pain Management, and Intensive Care, Udayana University, Sanglah General Hospital, Denpasar-Bali, Indonesia ${ }^{3}$ Lecturer of Department of Anesthesiology, Pain Management, and Intensive Care, Udayana University, Sanglah General Hospital, DenpasarBali, Indonesia
Cite this article:

Setiawan D, Senapathi TGA, Budiarta IG,

Aribawa IGNM. Contact force exerted on the maxillary incisors by direct laryngoscopy with McGrath video laryngoscope in predicted difficult intubation. Neurologico Spinale Medico Chirurgico. 202I.4(2)73-77. DOI:

I 0.36444/nsmc.v4i2. I62

Corresponding author:

Doddy Setiawan

Resident, Department of Anesthesiology, Pain Management, and Intensive Care, Udayana University, Sanglah General Hospital, DenpasarBali, Indonesia

ddsbius2017@gmail.com

\begin{abstract}
Patients with difficult airways who are going to undergo surgery under general anesthesia require special consideration from an anesthesiologist. Knowing the most significant risk of morbidity and mortality is often due to difficult cases of airway management. One of the most common complications and often becomes lawsuits in the field of anesthesia is dental trauma that occurs during the intubation process due to contact from laryngoscope blade to the teeth. This descriptive study will show the measured force exerted on the maxillary incisors at the time of performing laryngoscopy using a McGrath video laryngoscope in patients with a potentially difficult intubation (LEMON criteria $\geq 3$ ). The contact force exerted on the maxillary incisors is measured using a special instrument. The contact force exerted on the maxillary incisors in patients with a potentially problematic airway was discovered to vary.
\end{abstract}

Keywords: General anesthesia, Laryngoscopy, Video laryngoscopy, McGrath, Difficult intubation

\section{Introduction}

Patients with difficult airway is quite common and some of them may undergo surgery under general anesthesia requiring intubation for endotracheal tube placement. In addition, endotracheal intubation is also carried out in several conditions other than for surgical purposes, such as in patients who experience airway problems due to many things, such as accidents in the facial area, decreased consciousness, critical illness conditions, etc. Complications due to intubation will increasingly occur in the presence of the patient's condition with difficult airway.

Dental trauma is one of the most common complications due to intubation. ${ }^{1,2}$ The incidence ranges from $0.06 \%$ to $12 \%$. Of all these cases, maxillary incisors were the most frequently traumatized by laryngescopy. ${ }^{2-7}$ Generally, trauma to the upper incisors occurs due to pressure on the incisors from the laryngoscope blade because it is used as a fulcrum in the intubation process. ${ }^{4}$ Regarding the mechanism of injury, it is justified to assume that the amount of force exerted onto teeth correlate with the risk of trauma. ${ }^{8}$ 
Patients with difficult airway conditions will cause complications in the maxillary incisors more frequently. It is said that patients with difficult airway conditions have a 20.8 times chance of experiencing complications in teeth compared to patients without airway complications. ${ }^{4,6,9}$

There are many scoring systems for predicting difficult airways, especially difficult conditions of intubation. The LEMON criterion is one of them and is a good method and is able to assess risk stratification in difficult intubation. ${ }^{10}$ Patients with total values in the LEMON criteria $\geq 3$ have the possibility to face difficult intubation conditions. $^{11}$

While the conventional laryngoscope has been routinely used for tracheal intubation, video laryngoscopes have recently been developed and are being utilized in clinical practice. Previous research has demonstrated that video laryngoscopes lead to less contact force exerted on the oral structures, during intubation attempts. ${ }^{12,13}$ This report presents a series of cases documenting contact force exerted on the maxillary incisors by McGrath video laryngoscope during intubation attempt.

\section{Methods}

This is a cross-sectional descriptive study and we observed 20 patients aged 18-64 years who agreed to be recorded. These patients are predicted to have difficult airway conditions that have a LEMON (Look, Evaluate, Mallampati, Obstruction, and Neck Mobility) criteria of $\geq 3$, and will undergo surgery under general anesthesia at Sanglah General Hospital, Bali. Patients with physical status ASA 1-3 were included in this study. Patient with unstable hemodynamic value before the induction and without maxillary incisor tooth were excluded. We collected the subjects using the consecutive sampling method. The results will be presented in a table and described in range and mean for reported LEMON score and the contact exerted force on the maxillary incisor. This study has been approved by the institutional review board of our university with the clearance number 1617/UN14.2.2.VII.14/LT/2021.

The contact exerted force on the maxillary incisor is measured using an instrument called the Laryngoscope Pressure Meter (FSR 402) and using units in Newton (N). All subjects received the same medication for induction of anesthesia.

\section{Results}

Of the 20 subjects included, 10 subjects were male and 10 female subjects. With the youngest age is 18 years and the oldest age is 60 years. Of the 20 subjects, 7 cases were categorized as overweight patients (BMI $>25 \mathrm{~kg} / \mathrm{m} 2$ ), with the highest BMI being $46.8 \mathrm{~kg} / \mathrm{m} 2$. Based on the LEMON criteria, there were 5 cases with facial trauma, 10 cases with a large incisor, 4 cases with beard in the patient, 9 cases with a large tongue, 12 cases with an interincisor distance of less than three fingerbreadths, 11 cases with a distance mentohyoid less than three fingerbreadths, 14 cases with thyrohyoid distance less than two fingerbreadths, 12 patients with Mallampati $\geq 3,3$ cases with airway obstruction, and 9 patients with limited neck mobility.

Table 1. Summary of LEMON score and the contact force exerted on the maxillary incisors be McGrath laryngoscope

\begin{tabular}{|c|c|c|c|c|}
\hline No. & Laryngoscope & $\begin{array}{c}\text { LEMON } \\
\text { score }\end{array}$ & $\begin{array}{c}\text { Force exerted } \\
\text { on the } \\
\text { maxillary } \\
\text { incisors (N) }\end{array}$ & Complication \\
\hline 1 & McGrath & 4 & 6 & $\begin{array}{l}\text { Gingiva } \\
\text { bleeding }\end{array}$ \\
\hline 2 & McGrath & 5 & 3 & \\
\hline 3 & McGrath & 6 & 3 & \\
\hline 4 & McGrath & 6 & 4 & \\
\hline 5 & McGrath & 3 & 2 & \\
\hline 6 & McGrath & 3 & 5 & \\
\hline 7 & McGrath & 6 & 5 & \\
\hline 8 & McGrath & 4 & 6 & \\
\hline 9 & McGrath & 5 & 5 & \\
\hline 10 & McGrath & 5 & 4 & \\
\hline 11 & McGrath & 6 & 5 & \\
\hline 12 & McGrath & 6 & 6 & \\
\hline 13 & McGrath & 5 & 4 & \\
\hline 14 & McGrath & 6 & 5 & \\
\hline 15 & McGrath & 5 & 5 & \\
\hline 16 & McGrath & 5 & 4 & \\
\hline 17 & McGrath & 6 & 4 & \\
\hline 18 & McGrath & 6 & 6 & \\
\hline 19 & McGrath & 6 & 4 & \\
\hline 20 & McGrath & 5 & 8 & \\
\hline
\end{tabular}

The total of LEMON criteria ranged from 3 to 6 . The contact force exerted on the maxillary incisors due to McGrath video laryngoscope ranged from 2 to 8 . The smallest contact force was found 
in the case of a 28 years-old woman (BMI $20.8 \mathrm{~kg} / \mathrm{m}^{2}$ ) who underwent oncology surgery, with a total LEMON score of 3 (large incisor, less than three fingerbreadths mentohyoid distance, less than two fingerbreadths thyrohyoid distance). While the greatest contact force was found in the case of an 18 years-old woman (BMI $25.8 \mathrm{~kg} / \mathrm{m}^{2}$ ) who underwent neck abscess surgery, with a total LEMON score of 5 (two fingerbreadths interincisor distance, two fingerbreadths mentohyoid distance, one fingerbreadth thyrohyoid distance, Mallampati III, and limited neck mobility). Of the 20 subjects, there was 1 incident of gum bleeding which was found in a 30-year-old woman who underwent plastic surgery due to maxillofacial fracture. This patient had a total LEMON score of 4 (facial trauma, large incisor, one fingerbreadth interincisor distance, and Mallampati III).

\section{Discussion}

Based on these results, it was found that the force exerted on the maxillary incisors by the McGrath laryngoscope varies in magnitude. Even with the same LEMON score, different pressure levels can be obtained. The mean LEMON criteria score was 5.15 , the mean maxillary incisor pressure caused by McGrath video laryngoscope was $4.7 \mathrm{~N}$.

In our study with patients had possible difficulty intubation, it was found that the force exerted on the maxillary incisors was in the range of 2-8 N. This number was not significantly different compared with the force exerted on the maxillary incisor by McGrath video laryngoscope in patient without difficult airway management as reported by Senapathi et al., in $2020 .{ }^{14}$ Senapathi et al., found the range of compressive forces exerted on the maxillary incisors due to McGrath laryngoscopes ranging from 2-7 N. The result in our study is in accordance with the result of other study which measured the force during introduction of video laryngoscope associated with Mallampati grade. The study ${ }^{15}$ found that the force in maxillary incisor was $5.6 \pm$ $3.7 \mathrm{~N}$ in subjects with Mallampati grade III.

Shippey et al., ${ }^{16}$ studied the use of the McGrath laryngoscope in the management of difficult and unsuccessful tracheal intubation and discovered that using the McGrath videolaryngoscope allowed for improved visibility of the glottic area and faster intubation action, reducing intubation difficulties. This is in accordance with the findings of our study, which was all the subjects was successfully intubated in the first attempt and the laryngoscope operator had a good visibility of glottic area before inserting the endotracheal tube. Only 1 case of complication (gum bleeding) in the use of the McGrath laryngoscope. However, our study did not record the time required for intubation.
In $2-8 \%$ of all general anaesthesia cases, difficult laryngoscopy occurs. Intubation failure is uncommon, and difficult intubation is uncommon. ${ }^{16}$ When the glottis opening cannot be visualized, a variety of procedures have been utilized to intubate the trachea. The Difficult Airway Society recommends adjusting head and neck position, providing appropriate muscle relaxation, and switching to a different laryngoscopy device at first. When conventional laryngoscopy fails, video laryngoscopy is quickly becoming an established technique that can provide a clear image of the larynx. The procedure is quite simple to learn, and there have been few reported difficulties. Difficult intubation is the main risk factor for dental injury, other risk factor include poor dentation and pre-existing craniofacial abnormalities. ${ }^{17}$

The complication (gum bleeding) due to laryngoscopy in this study were found in maxillary incisors tooth. Because of their anterior placement, the central incisors are subjected to the stresses of oral instrumentation, including direct laryngoscopy. They are anchored to the bone usually by a single root and have a small cross-sectional area rendering them susceptible to damage by external forces. ${ }^{7}$ The most common cause of perioperative dental injury is a combination of preexisting dental pathology and an external force. Avulsions, fractures and dislocations occur most frequently during laryngoscopy manoeuvres described. ${ }^{2}$ Both beginner and expert anaesthetists, as well as difficult and easy intubations, have the potential to cause dental damage.

Other factors that have been identified as facilitators of dental injury in the literature include the impact on the dental arch during laryngoscopy, in combination with inadequate intubation technique and the patient's anatomic characteristics (oral disorders, presence of prosthesis, previous history of difficult intubation, previous neck surgery, chemotherapy or prior radiotherapy to the oral cavity, tongue tumor, oral trauma, and an impaired patient). ${ }^{2}$

Tooth contact is linked to a high Mallampati score (three or four), poor mandibular subluxation, limited head and neck movement (less than 90 degrees), and a small inter-incisor gap (less than five centimeters). ${ }^{4}$ Patients with a Mallampati score of 3 and prominent 'buck' teeth, for example, have been observed to have blade-tooth contact in over $90 \%$ of intubations.

Biting forces in the range of 150-200 $\mathrm{N}$ can be tolerated by the arch of incisors along their axis, and healthy teeth are intended to endure these forces. ${ }^{7}$ Teeth are vulnerable to damage when their structural integrity is compromised by dental caries or periodontal disease and are restored or replaced by artificial material. Teeth are also 
vulnerable when excessive force is applied, which the teeth and their roots are not designed to withstand. Patients with pre-existing dental pathology are five times more likely to suffer dental trauma. Three out of four incidences of bleeding gums were discovered in individuals with facial injuries in this case series.

There are many factors attributing to the force applied on maxillary incisors during laryngoscopy and/or tracheal intubation. Variables that might influence the measured laryngoscope compression could be related to the patient (e.g., sex, weight, height, the narrowness of the palate, and neck thickness), the person intubating the patient (e.g., experience, manipulation techniques, and forces used), and the anesthetic technique (e.g., the degree of muscle relaxation, manual inline stabilization performed, and the type and size of the blade used).

\section{Conclusion}

The contact force exerted on the maxillary incisors due to laryngoscopy in patients with possible difficult intubation varies in value. The maxillary incisor pressure in patients with possible difficult intubation using McGrath video laryngoscope in this case series was between 2-8 $\mathrm{N}$ and there was 1 incidence of complication during the laryngoscopy. In fact, many factors influence the appearance of complications and the amount of pressure on the maxillary incisors during laryngoscopy.

\section{Declaration of patient consent}

The authors certify that they have obtained all appropriate patient consent forms. In the form the patient (s) has/have given his/her/their consent for his/her/their images and other clinical information to be reported in the journal. The patients understand that their names and initial s will not be published, and due efforts will be made to conceal their identity, but anonymity cannot be guaranteed.

\section{Financial support and sponsorship}

None

\section{Conflicts of interest}

There are no conflicts of interest.

\section{References}

1. Lockhart PB, Feldbau EV, Gabel RA, et al. Dental complications during and after tracheal intubation. $J$ Am Dent Assoc. 1986;112(4):480-3. DOI: 10.14219/jada.archive.1986.0035

2. Sousa JMBR, Mourão JI B. Tooth injury in anaesthesiology. Brazilian $J$ Anesthesiol. 2015;65(6):511-8. DOI: 10.1016/j.bjane.2013.04.011

3. Owen H, Waddell-S I. Dental trauma associated with anaesthesia. Anaesth Intensive Care. 2000;28(2):133-45. DOI: 10.1177/0310057X0002800202

4. Windsor J, Lockie J. Anaesthesia and dental trauma. Anaesth Intensive Care $\quad$ Med. 2008;9(8):355-7. DOI:10.1016/j.mpaic.2008.06.006

5. Vogel J, Stübinger S, Kaufmann M, et al. Dental injuries resulting from tracheal intubation - A retrospective study. Dent Traumatol. 2009;25(1):73-7. DOI: 10.1111/j.1600-9657.2008.00670.x

6. Basavaraju A, Slade K. Dental damage in anaesthesia. Anaesth Intensive Care Med. 2020;21(9):453-6. DOI: 10.1016/j.mpaic.2020.06.004

7. Basavaraju A, Slade K. Dental damage in anaesthesia. Anaesth Intensive Care Med. 2017;18(9):438-41. DOI: 10.1016/j.mpaic.2017.06.002

8. Schieren M, Kleinschmidt J, Schmutz A, et al. Comparison of forces acting on maxillary incisors during tracheal intubation with different laryngoscopy techniques: a blinded manikin study. Anaesthesia. 2019;74(12):1563-71. DOI: 10.1111/anae.14815

9. Newland MC, Ellis SJ, Peters KR, et al. Dental injury associated with anesthesia: A report of 161,687 anesthetics given over 14 years. $J$ Clin Anesth. 2007;19(5):339-45. DOI: 10.1016/j.jclinane.2007.02.007

10. Mshelia D, Ogboli-Nwasor E, Isamade E. Use of the "L-E-M-O-N" score in predicting difficult intubation in Africans. Niger J Basic Clin Sci. 2018;15(1):17. DOI: 10.4103/njbcs.njbcs_25_16

11. Ji SM, Moon EJ, Kim TJ, et al. Correlation between modified LEMON score and intubation difficulty in adult trauma patients undergoing emergency surgery. World $J$ Emerg Surg. 2018;13(1):1-6. DOI: 10.1186/s13017-018-0195-0

12. Lee RA, Van Zundert AAJ, Maassen RLJG, et al. Forces applied to the maxillary incisors by video laryngoscopes and the Macintosh laryngoscope. Acta Anaesthesiol Scand. 2012;56(2):224-9. DOI: 
10.1111/j.1399-6576.2011.02541.x

13. Kato Y, Sakuma Y, Momota Y. Comparison of the contact force exerted on teeth by conventional macintosh laryngoscope versus video laryngoscopes. Anesth Prog. 2018;65(3):151-5. DOI: 10.2344/anpr-65-03-01

14. Senapathi TGA, Widnyana IGM, Mahaalit IGN, et al. Contact force exerted on the maxillary incisors by direct laryngoscopy with Macintosh and McGrath video laryngoscopy. Bali J Anesthesiol. 2020;4(4):194. DOI: 10.4103/BJOA.BJOA_100_20

15. Lee RA, Van Zundert AAJ, Maassen RLJG, et al. Forces applied to the maxillary incisors during video-assisted intubation. Anesth Analg. 2009;108(1):187-91.

DOI:
16. Shippey B, Ray D, McKeown D. Use of the McGrath $\AA$ videolaryngoscope in the management of difficult and failed tracheal intubation. $B r J$ Anaesth. 2008;100(1):116-9. DOI: 10.1093/bja/aem303

17. Touman AA, Stratakos GK. Long-term complications of tracheal intubation. In: Tracheal Intubation. 2018. p. 89-112.

10.1213/ane.0b013e31818d1904 